\title{
Glocalizing ELT: From Chinglish to China English
}

\author{
Xing Fang \\ English Language Centre, Shantou University, Shantou, China \\ Email: xfang@stu.edu.cn
}

\begin{abstract}
In face of the reality that English has germinated into a global language whose hegemonic effect has posed a threat to the existence of many other languages, China should glocalize English language teaching by developing Chinglish into China English - a new English variety that maintains high intelligibility in the global context and incorporates rich local linguistic and cultural characteristics. Only in this way can China prevent its English learners from acquiring a global tongue at the expense of local indigenous languages and cultures. Furthermore, China's English education or EFL education in general, when converted from manufacturing "culture receivers" to nurturing "culture senders", will be more effective in reinforcing English learners' sense of pride in their native cultural identity and increasing their confidence in intercultural communication on the global stage.
\end{abstract}

Index Terms - China English, Chinglish, glocalization, localization, intercultural communication

\section{INTRODUCTION}

The motto "Think global, act local", originated by Rene Dubos, has nowadays been used in a variety of contexts, including English education pedagogy. This phrase has the implication that being a competitive player in the fastglobalized world requires communication with the world and taking advantage of local resources. With regards to English education, particularly in countries where English is not spoken as a native language, teachers should take the responsibility to consider how to accommodate this world language in the classroom so that it may serve local needs without causing damage to local resources - impairing the development of local indigenous languages and cultures. Grounded on this belief, this paper will commence by reviewing the causes of the global spread of English and its negative effects. Then, it will revisit the concept of language localization, which is seen as an effective means to combat the threat that the world language is casting upon the existence of local indigenous languages. Also, it will discuss the standards for validating localized Englishes as legitimate English varieties. Subsequently, it will describe the general situation of English education in China and propose the progression of Chinglish into China English in the Chinese context, followed by a brief discussion of the potential of China English developing into a new legitimate English variety. It will then end with an examination of the linguistic and cultural contributions of China English, coupled with advice on how teachers in China may materialize the teaching of China English in local classrooms.

The initial spread of English began with British and American colonialism and the migration of English-speaking individuals to other regions of the world during the nineteenth and twentieth centuries. As Britain and the United States took turns to become the world's leading economic power through industrial capitalism in the past three centuries, advanced technological and scientific inventions mushroomed in these two countries, which further fueled the spread of English. People who wanted to learn about these innovative technologies needed to learn English so as to understand new terminology and talk to the English-speaking inventors and manufacturers (Crystal, 1997). As for the factors that are accountable for the current spread of English and the macro-acquisition of the language within existing speech communities, controversial voices are heard among linguists and educators. For example, Phillipson (1992) contends that the global spread of English is a matter of deliberate policy on the part of core English-speaking countries to maintain dominance over periphery countries, in many cases, developing countries. Also, he (1992, p.47) coins the term "linguistic imperialism" and posits it as a type of cultural imperialism by claiming that "the dominance of English is asserted and maintained by the establishment and continuous reconstitution of structural and cultural inequalities between English and other languages". However, Widdowson (1997), on the grounds of the current uses of English, argues that the global currency of English is attributed to the fact that the language is now central to a wide variety of specific purposes ranging from international relations to popular culture to academia. Moreover, McKay (2002, p.24) refutes Phillipson's "linguistic imperialism" by emphasizing that "the spread of English is ... a complex process brought about both by those who actively promote the language and those who consciously choose to learn it", and she further explains that many individuals learn English in order to claim access to such things as scientific and technological information, global economic trade, and higher education, the majority of which are English-based in the fast-globalized world (p.21).

Given that English has successfully sprouted into a vital linguistic tool of international power, the author of this paper believes that the language with its manifold benefits may cause people in non-native English speaking countries to 
prioritize English learning and neglect the development of their native tongue. This opinion finds due support from Xu (2007), a well-known expert of Chinese linguistics, who anxiously points out that Chinese people's literacy in Chinese has currently been declining, and the ever worsening situation even extends to well-educated people. To him, the major reason for this phenomenon is that in China English is being considered more valuable than Chinese so that people are willing to devote more time to improving their English competence. In addition, MacPherson and Beckett (2008) offer another example of the Uighurs in Northwestern China coping with great pressure to learn English as well as Mandarin Chinese for their basic survival and making local languages and knowledge irrelevant. Similar cases of language devaluation and replacement have also occurred in Singapore (Gopinathan, 1998) and Nigeria (Schaefer \& Egbokhare, 1999).

In order to keep up with the trend of globalization and meanwhile counteract the hegemonic effect of English which can marginalize and impoverish local indigenous languages, non-native English learners/ speakers in Outer Circle countries (the countries where English is an inherited second language) (Kachru, 1985, pp.12-15) have created some new localized varieties of English, such as Singapore English and Indian English, through which they have managed to preserve the phonological, lexical, grammatical and rhetorical traits of their native language and find an expression of their national and cultural identity in the course of speaking the global language (Carter \& Nunan, 2001, p.4). However, new Englishes soon give rise to concerns over standards in English as international language. Some linguists refuse to acknowledge Outer-Circle Englishes as Standard English, and some others are worried that allowing for a wide variety of norms would reduce the intelligibility of English as an international language (EIL). Therefore, in order for the new Englishes to gain wider acceptance, it is crucial to consider what is meant by Standard English and whether or not intelligibility would cause an insurmountable problem that narrows the path of English localization.

The Longman Dictionary of Applied Linguistics (Richards, Platt \& Weber, 1985) defines Standard English as the variety of English that has the highest status in a community or nation and is based on the speech and writing of welleducated people. Besides, it should be: a) used in the news media and in literature; b) described in dictionaries and grammars; c) taught in schools and taught to non-native speakers when they learn English as a foreign language. Grounded on this definition, Singapore English, as an example of Outer-Circle Englishes, can be recognized as a standard English variety, because it is generally spoken by the socially dominant group of the country (the rich and powerful as well as the educated elites), and it is used for governmental administration, taught in schools and used in the mass media (Lick \& Alsagoff, 1998, p.282).

In approaching the issue of mutual intelligibility among varieties of EIL, McKay (2002, pp.52-53) proposes a tripartite definition of intelligibility that involves intelligibility (recognizing an expression), comprehensibility (knowing the meaning of the expression), and interpretability (knowing what the expression signifies in a particular sociocultural context), and then she claims that it is usually interpretability that causes the greatest problems in the use of EIL for cross-cultural communication since interpretability entails questions of culture and context. However, she further maintains, "When English is used cross culturally, it is very possible that the speakers will work together to achieve interpretability." Hence, people in Outer Circle countries should not be discouraged from speaking localized Englishes but ought to learn some communicative strategies that can help them accommodate linguistic and cultural differences and repair communication failures.

As indigenized Englishes in Outer Circle countries are gradually claiming their legitimate status, the author of this paper deems that people in China should also launch a revolution of English use in order to offset the negative effect that the powerful global language is inflicting upon local indigenous languages. As a country with a humongous group of English learners and users, China has a great potential of constructing another English variety that reflects and consolidates her unique civilization. Before outlining the Chinese variety of English, it is important to first gain some knowledge of the general situation of English education in this country.

Since China undertook tremendous social reforms and gradually opened herself up to the outside world during the past three decades, English has become the principal medium for the world to know this country and the country to establish communications with the world. Designated as a compulsory school subject that penetrates the whole educational system, English has enabled Chinese learners to help the government establish and maintain healthy international relationships, to conduct profitable international business and trade, and to learn about latest social, scientific and technological advances in the world. With these undeniable benefits, English is rapidly transforming the social conditions of the country as well as people's attitude towards local indigenous language, as noted earlier in this paper, and Chinese traditional culture (Guo and Beckett, 2007, p.124). At schools, western cultural norms and values prevail in almost all English learning textbooks that were either originated in the UK or the US or developed in China in the name of authenticity, leaving very limited room for including the discussion of local cultures and issues. British English and American English are serving as role models for English instruction in all public schools without change. Such practices cause learners to struggle painstakingly to achieve native-like English, which is, however, highly unattainable in an EFL context. What is worse, when foreigners in China hope to learn about some common Chinese cultural/ societal phenomena from these learners, they often fail to offer a sound and in-depth explanation in even plain English, because: first, they have not been taught to express or describe concepts and events that are laden with local culture; second, they have spent a large amount of time learning English and hence weakened the study of Chinese and Chinese culture. 
In order to mitigate the exacerbation of this situation, a new model of English must be established in China. And this new English should maintain high intelligibility in the global context and incorporate Chinese elements for celebrating local identity and native cultural values and beliefs.

To obtain this goal, great efforts should be made to channel a widely used Chinese style of English (Chinglish) into the right track. Chinglish, as defined by Pinkham $(2000$, p.1) is a misshapen and hybrid language that is neither English nor Chinese, for example, "Be cautious to slip." (Caution Wet Floor). Guan (2007) further adds that Chinglish is an interlanguage and its occurrence is the result of negative transfer of the mother tongue. The divergence of Chinglish from the standard norms of Englishes of Inner Circle countries (the countries where English is the first language) (Kachru, 1985, pp.12-15) can cause great confusion and incomprehension on various linguistic levels. On the lexical level, word for word translation (e.g. self walk car instead of bicycle) and literal translation (e.g. free love instead of free choice of marriage partner) may result in unintelligible or imprecise expressions in the target language. On the syntactic level, Chinese ways of constructing sentences, for instance, piling clauses together without using conjunctives, may lead to poor coherence of narration. On the discourse level, confusion may also arise from the indirect manner that ideas and/or theme are presented. In face of this improper use of English among many Chinese, Li (1993) proposes the concept of China English in hopes of steering the development of a legitimate English variety in China. He distinguishes China English from Chinglish by claiming that China English, free from mother tongue's negative interference, is shaped by combining the core linguistic norms of Inner-Circle Englishes and Chinese cultural elements that participate in communication by means of phonetic translation, borrowing and meaning reproduction (p.19). The reason for China English to be bound up with Inner-Circle Englishes for provisions of linguistic norms is that China belongs to Expanding Circle countries (the countries where English is a foreign language) (Kachru, 1985, pp.12-15), so there is no regular internal use of English in the country for linguistic innovations to be established as conventions and further codified as language standards and norms (Kachru, cited in McKay, 2002, p.54). However, this does not hinder Chinese characteristics from permeating the local use of English. Without violating the norms of Inner-Circle Englishes that govern sound, vocabulary, grammar, syntax and discourse, China English can embrace words or phrases like netizen (cyber citizen), taikongnaut (in contrast with cosmonaut and astronaut), exam-oriented education, association of fellow townsmen, grain-for-green (a government policy to convert farmland into forests or grassland to prevent soil erosion), and it can also incorporate expressions like $a$ land of fish and rice (an affluent land, in contrast with a land of honey and milk), "draw water with a bamboo basket" (all efforts will be in vain, because water will leak out from an ordinary basket made of bamboo), "paper cannot wrap up a fire" (truth will come to light sooner or later), "he is restless like an ant on a hot pan" (a cat on hot bricks), "there cannot be waves without wind" (things always happen for a reason), "a swan feather as a gift may look worthless, but it comes from afar and carries with it all the good intentions of the sender". All these lexical items and syntactic expressions afford a clear demonstration of how Chinese concepts can be phrased and regenerated through English and therefore shed new color on the global language.

The potential for China English to develop into a Standard English variety rests on a couple of positive factors: firstly, some Chinese expressions have been absorbed into Inner-Circle Englishes, for example, china, silk, dim sum, choy sum, lychee, ginseng, tea, wok, chopsticks, kowtow, typhoon, tycoon, brainwash, long time no see (Chinglish); secondly, translation can not always build bridge between two disparate languages, because cultural concepts and items in one setting may find no equivalence in another (Guan, 2007), therefore China needs its own way to express unique things such as chengguan (urban management officers, whose main obligation is to ward off street vendors without license and are often involved in some low-level crime and/ or public disorder), spring transportation (the heavy traffic load around the time of Chinese New Year), and skin scraping and fire cupping (practices of traditional Chinese medicine); thirdly, a number of Chinese words, such as tofu, soy, gungho, kowtow, chop suey, bonsai, taichi, have been inscribed in dictionaries like Cambridge Advanced Learner's Dictionary, and some others have been used in mass media and literature, such as kung fu and sifu in "Kung Fu Panda", mahjong in "The Joy Luck Club" and guasha in "Guasha"; fourthly, an increasing number of Chinese linguists and English educators have realized the significance of English localization in China and are committing themselves to the promotion of China English as well as Chinese culture.

The idea of localizing the global language without deforming it (as in Chinglish) may be phrased as the glocalization of English. China English, also known as a glocalized English variety, yields rich benefits for the nation and the world. Firstly, China English enables the rest of the world to better learn about China-related issues or events and learn from the Chinese experience. For instance, One Country, Two Systems (a government policy for peaceful reunification implemented on Hong Kong SAR and Macau SAR) may provide a good lesson on international dispute settlement. Harmonious Society, a term originated in the 4th Plenary Session of the 16th CPC Central Committee and reflecting the Chinese government's determination to build a new socialist countryside, may shed some light on achieving a balanced urban-rural development. Secondly, China English allows valuable elements of Chinese traditional culture to be better preserved, developed and promoted. For example, words like fengshui and taichi have successfully brought the ancient Chinese art and life philosophy under spotlight on the global stage, drawing immense attention and ongoing fascination from the whole world. With Chinese culture and traditions growing more and more popular in the world, Chinese English speakers will too be gaining the power of discourse in intercultural communication, because they are no longer passive culture receivers but culture disseminators. This, in return, may reinforce their sense of pride in their native cultural identity and serve as a strong incentive for them to further explore and protect Chinese cultural legacies. 


\section{TEAChing China English: A Chinese CONTEXT}

This section will mainly put forward some suggestions and possible approaches of teaching China English, which can easily be adapted for use in other linguistic and cultural contexts where English is sought to be glocalized.

1. It is essential for teachers to make students aware of the difference between China English and Chinglish. This can often be achieved through compare-and-contrast exercises. Firstly, the teacher should assign students to create a corpus of English use by going to streets, subways and any other public places to take photos of signs in English, or going to restaurants to collect English translation for Chinese dishes, or recording English news broadcast about China from TV, or making copies of each others' written assignments (e.g. essays). After that, the teacher should work with students examining the spoken and/or written discourses within the corpus and identifying what is acceptable (China English) and what is not (Chinglish). Eventually correction will be given to unacceptable expressions. Below are some examples:

1) Chinglish samples from some public signs:

"Don't throw away your rubbish." (Don't litter!)

"If you are stolen, call the police." (Report thefts to the police.)

"Only for deformed people" (Disable Only)

2) Chinglish samples from student's essays:

"My mother is one of the most vital people in my life because of her hobbits." (hobbies)

"And the memories you leave here will not fake away by time." (fade away)

"Therefore, if you know Cantonese, take out your heart to help others." (take actions)

3) China English samples from some public signs and billboards:

"Please cherish the grass." (In contrast with "Keep off the grass!")

"Zhanjiang is our home. Everyone needs to keep it clean."

"It makes no difference if a baby is a boy or a girl." (an appeal for change on the traditional "son-preference" ideology)

4) China English samples from student's essays:

"I really like the floating softness of the cloudy hands posture." (Taiji posture)

"... the whole class sat by the reservoir and appreciated the moon." (a Mid-autumn Day cultural practice)

"Familial affection is the needle in my mother's hand that pulls the thread, the fan in my father's hand that drives away mosquitoes, and the bicycle that my brother rides to send me to school."

2. Students can be assigned to work individually or in groups to collect and compare English and Chinese proverbs or idioms that are equivalent or similar in meaning. Through learning the cultural similarities and differences that abound in proverbial and idiomatic expression of social reality, students may be able to interpret Chinese (traditional) concepts and values more precisely to foreigners. Because when they quote a Chinese saying in English, they can relate it to its foreign counterpart and further explain, if necessary, why the same theme is approached in different ways. For example, "the grain has been cooked into rice" or "the wood has been made into a boat" can be juxtaposed with "what is done can not be undone".

3. Students can also be required to role play different scenarios of intercultural communication where they need to exchange cultural information. Situational dialogues between a Chinese tourist guide and foreign visitors at a tourist spot, or Chinese sellers and foreign shoppers at a Chinese antique or fabric market, or a Chinese and his/her foreign friends at a tea/ Chinese opera house, for instance, can proffer rich opportunities for students to use China English to initiate intercultural communication and decode Chinese culture.

4. In terms of textbook use, teachers should select the books that incorporate rich Chinese elements or add materials about China that are written by Chinese or international authors, such as novels, essays, travelogues, news articles, investigation reports and translated Chinese classics. Moreover, activities concerning Chinese culture and China English may also be integrated into text learning. For example, following a text introducing how to cook Western food, students can be asked to work in groups to create a blog in English introducing Western and Chinese food culture and providing recipes for some popular Western and Chinese food. This activity may also be used for approaching cultural themes like traditional holidays, marriage, public rituals and folktales.

Last, but not the least, teachers should make efforts to broaden their own knowledge of Chinese and world cultures and find paths for deepening their own intercultural awareness. Only then can they become more capable of presenting and interpreting cultural information as well as commenting on intercultural exchanges in class.

\section{CONCLUSION}

This paper is mainly intended for exploring what language policy China should follow in coping with the detrimental influence that the global language English has caused on local indigenous languages. It also hopes to provide a solution to other (Expanding Circle) countries where people are struggling with the same issue. The author started the discussion with a brief review of the global expansion of English and its negative repercussions. Then, he moved to focus on the growth of Outer-Circle Englishes, which are able to prevent the speakers from acquiring a global tongue at the expense of local indigenous languages and cultures. Inspired by these new varieties of Englishes, the author proposed regulating the local use of English (Chinglish) in China and developing a legitimate glocalized form of Chinese English (China 
English). He further affirmed that the development of China English would gain Chinese people the power of discourse in intercultural communication and consolidate China's unique culture in a world with increasing uniformity. In the end, he offered some teaching methods and techniques for addressing China English in the classroom.

\section{REFERENCES}

[1] Carter. R. \& D. Nunan. (2001). The Cambridge Guide to Teaching English to Speakers of Other Languages. Cambridge: Cambridge University Press.

[2] Crystal, D. (1997). English as a Global Language. Cambridge: Cambridge University Press.

[3] Gopinathan, S. (1998). Language policy changes 1979-1997: Politics and pedagogy. In Gopinathan, S., A. Pakir, W. K. Ho \& V. Saravanan (eds.), Language, Society and Education in Singapore. Singapore: Times Academic Press.

[4] Guan, M. (2007). China English, Chinglish and English learning. US-China Foreign language, 5(5), 6-11.

[5] Guo Y. \& G. H. BecKett. (2007). The hegemony of English as a global language: Reclaiming local knowledge and culture in China. Convergence, 40 (1-2), 117-131.

[6] Kachru, B. B. (1985). Standards, codification and sociolinguistic realism: The English language in the outer circle. In Quirk R. \& H. G. Widdowson (eds.), English in the World: Teaching and Learning the Language and Literature. Cambridge, England: Cambridge University Press.

[7] Li, W. Z. (1993). China English and Chinglish. Beijing: Foreign Language Teaching and Research Press.

[8] Lick, H. C. \& L. Alsagoff. (1998). Is Singlish grammatical?: Two notions of Grammaticality. In Gopinathan, S., A. Pakir, W. K. Ho \& V. Saravanan (eds.), Language, Society and Education in Singapore. Singapore: Times Academic Press.

[9] MacPherson, S. \& G. H. Beckett. (2008). The hidden curriculum of assimilation in modern Chinese education: Fueling indigenous Tibetan and Uygur cessation movements. In Bekerman Z. \& E. Kopelowitz (eds.), Cultural Education/Cultural Sustainability: Identity, Tolerance, and Multicultural Issues in Minority, Diaspora, Indigenous Education. Mahwah, NJ and London: Lawrence Erlbaum.

[10] McKay, S. L. (2002). Teaching English as an International Language: Rethinking Goals and Approaches. Oxford: Oxford University Press.

[11] Phillipson, R. (1992). Linguistic Imperialism. Oxford: Oxford University Press.

[12] Pinkham, J. (2000). The Translator's Guide to Chinglish. Beijing: Foreign Language Teaching and Research Press.

[13] Richards, J., J. Platt \& H. Weber. (1985). Longman Dictionary of Applied Linguistics. London: Longman.

[14] Schaefer, R. P. \& F. O. Egbokhare. (1999). English and the pace of endangerment in Nigeria. World Englishes, 18(3), $381-91$.

[15] Widdowson, H. G. (1997). EIL, ESL, EFL: Global issues and local interests. World Englishes, 16(1), 135-46.

[16] Xu, J. L. (2007). Overemphasizing English learning haunts China. People's Daily (overseas version), February 1, A2.

Xing Fang was born on in 1981 in Hunan, China. He obtained his Master degree in TESOL from the University of Sydney, Sydney, Australia in 2006.

Now he is currently a LECTURER at the English Language Centre of Shantou University, China. Prior to university teaching life, he worked with New Oriental Education \& Technology Group (Guangzhou Branch) and Alcanta College of Foreign Languages (Guangzhou, China) as an English trainer and instructor.

Mr. FANG is also a member of TESOL and IAWE (International Association of World Englishes). 